\title{
Endurance Exercise Induced Atrial Fibrillation (AF): Pathophysiology, Treatment and Prevention
}

\author{
Tawithep Leowattana ${ }^{1}$, Pathomthep Leowattana ${ }^{2}$ and Wattana Leowattana ${ }^{3 *}$ \\ ${ }^{1}$ Department of Medicine, Faculty of Medicine, Srinakharinwirot University, Bangkok 10110, Thailand \\ ${ }^{2}$ Department of Medicine, Faculty of Medicine, Siriraj Hospital, Mahidol University, Bangkok 10700, Thailand \\ ${ }^{3}$ Department of Clinical Tropical Medicine, Faculty of Tropical Medicine, Mahidol University, Bangkok 10400, Thailand \\ *Corresponding author: Wattana Leowattana, Department of Clinical Tropical Medicine, Faculty of Tropical Medicine, Bangkok \\ 10400, Thailand
}

\section{ARTICLE INFO}

Received: 崖 June 06, 2020

Published: 幽 June 18, 2020

Citation: Leowattana T, Leowattana P, Leowattana W. Endurance Exercise Induced Atrial Fibrillation (AF): Pathophysiology, Treatment and Prevention. Biomed J Sci \& Tech Res 28(3)-2020. BJSTR. MS.ID.004640.

\author{
ABSTRACT
}

The health benefits of regular moderate-intensity exercise are indisputable. Recently, concerns have been raised about atrial fibrillation (AF) risk of strenuous endurance exercise. On the other hand, most modest exercise intensity is associated with a decreased risk of AF. Many investigators indicated a J-shaped or U-shaped relationship between the broad range of physical activity and AF. The mechanism underlying the increased risk of $\mathrm{AF}$ with endurance exercise may be different from the pathophysiology of a reduced risk of moderate exercise. It was speculated that long-term endurance exercise may promote cardiac structural changes (dilatation and fibrosis), increase vagal tone, bradycardia, and inducing AF. It can cause serious symptoms that disturb the intensity of exercise activity and hence more attention should be considered to prevent AF during endurance exercise. Moreover, the reduction of exercise intensity will be the most effective prevention strategy to decrease AF risk.

Keywords: Atrial fibrillation; Endurance exercise; Arrhythmia; Physical activity; Vigorous exercise; Sedentary; U-shaped pattern; J-shaped pattern; Mahidol University

\section{Introduction}

The benefit of physical activity and exercise for the reduction of cardiovascular disease incidence, morbidity and mortality is an undoubted procedure [1,2]. Although the benefits of exercise have been scientifically proven and are well-established, recent studies have reported an increase in sudden cardiac death during or shortly after intense physical activity led researchers to question whether vigorous exercise was harmful or not $[3,4]$. The accumulating evidence from studies performed in the past 2 decades supports the premise that strenuous physical activity is not only able to trigger cardiac events, but can also promote the development of cardiovascular diseases in individuals with no previous cardiovascular abnormalities [5-8]. These research have focused on the identification of arrhythmias originating in the atrium or the right ventricle. Specifically, the role of exercise in the development of atrial fibrillation (AF) has been acknowledged. The significant of the endurance exercise induced AF as public health concerns was underscored for 2 reasons. Firstly, the lifestyles of young athletes are generally seen as a role model of a healthy way of life. Secondly, most exercise-induced heart conditions are diagnosed only in individuals engaged in vigorous exercise. Considering that the number of people undertaking intense forms of exercise has been steadily increasing for the past 20 years, without a doubt, the number of individuals affected by exercise-induced AF also progressively increased. Consequently, all health-care professional and policy makers needed to understand why and how these paradoxical effects of exercise-induced AF clearly, and how they should be approached. In this review, we demonstrated the evidence that endurance exercise significantly increases the risk of developing AF. Moreover, low physical activity and poor cardiorespiratory fitness (CRF) contributes to increased AF incidence. While regularly and moderately intense exercise may provide therapeutic benefit for patients with $\mathrm{AF}$ as well as a reduction of $\mathrm{AF}$ incidence in general population. 


\section{Atrial Fibrillation (AF)}

Atrial fibrillation (AF) is the most common sustained arrhythmia worldwide and can increase the risk of stroke, heart failure, dementia, and mortality. Both its incidence and prevalence increase with age, especially over 65 years. Hospitalizations as a result of AF are rising annually and AF is associated with a two fold increase in premature mortality, placing an urgent demand for strategies to reverse these trends [9-11]. There are many factors, besides age, that have been found to be associated with AF development, such as hypertension, male sex, central obesity, thyroid disease, previous heart failure or other cardiovascular diseases. Given the significant contribution of modifiable cardiovascular risk factors to the development of AF, favorable lifestyle behaviors such as physical activity and exercise are likely to contribute to a reduction in AF risk.

\section{Pathophysiology}

Trigger and Substrate: AF is characterized by very rapid and uncoordinated atrial activity. Conceptually, the initiation and maintenance of $\mathrm{AF}$ can be linked to the interaction between a trigger and the substrate. A trigger is a rapidly firing focus that can act as an initiator for arrhythmia, the maintenance of which generally requires a substrate, that is, electrophysiological, mechanical and anatomical characteristics of the atria maintain AF. Development of this substrate usually includes both electrical and structural elements of atrial remodeling. Electrical remodeling occurred from changes in the properties of ion channels affecting atrial myocardial activation and conduction. On the other hand, structural remodeling refers to alterations in the tissue architecture, both microscopically and macroscopically. There is a progression over time from a trigger-driven disease, through development of a functional atrial substrate, followed by predominant structural atrial remodeling [12]. These progressions correspond to the clinical AF which is often initially paroxysmal AF, after that progressing to persistent $\mathrm{AF}$ and finally permanent AF (Figure 1). Haïssaguerre and colleagues demonstrated that the muscular sleeves within the Pulmonary Veins (PVs) ostia served as the source of the ectopic beats which triggered AF in many patients with paroxysmal AF [13].

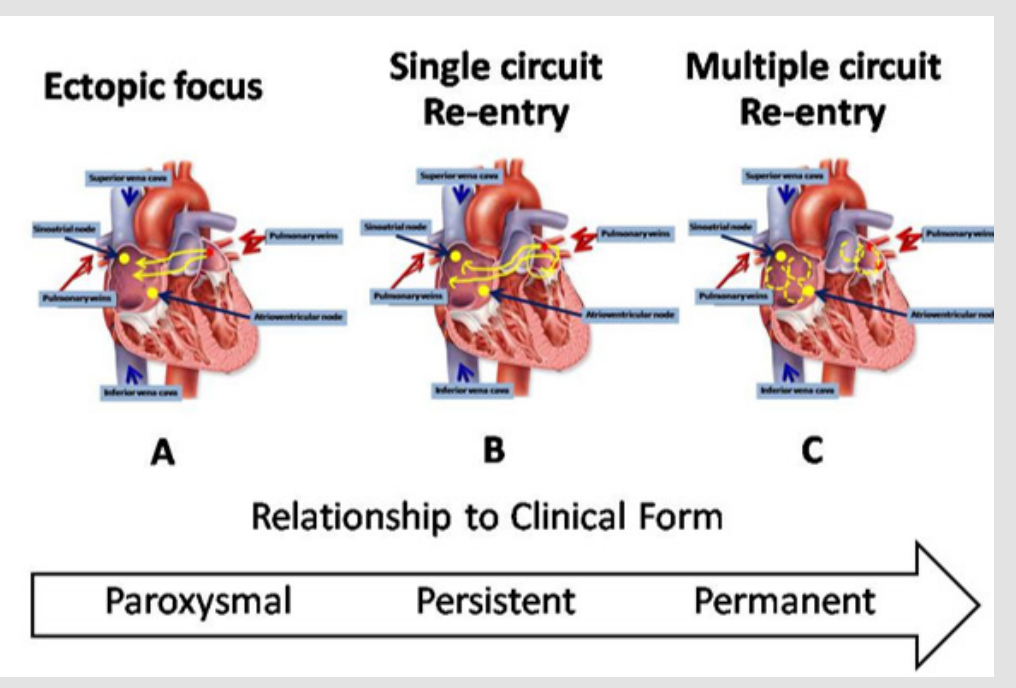

Figure 1: Progression in atrial fibrillation (AF) mechanisms over time.

A) Ectopic focus

B) Single circuit re- entry

C) Multiple circuit re-entry

Non-PVs triggers have also been established including the superior vena cava (SVC), coronary sinus, left atrial appendage, ligament of Marshall, crista terminalis and left atrial posterior free wall. Moreover, AF may also be triggered by atrioventricular nodal reentrant tachycardia and typical counterclockwise right atrial flutter. The thin structure and specific action potential properties of the PVs are contributory factor to the predisposition of arrhythmogenesis. The PVs cells have a higher resting membrane potential, lower amplitude of the action potential, smaller maximum phase 0 upstroke velocities and shorter action potential duration (APD). The role of the PVs in triggering AF was confirmed in multiple subsequent studies [14-16].
Atrial Electrical Remodeling: Electrical remodeling of the atria may be the result of $\mathrm{AF}$ and/or the result of hemodynamic derangements. The most significant pro-arrhythmic consequence of atrial electrical remodeling due to AF is the shortening of the refractory period due to down regulation of the Ca2+ current, accelerated repolarization and hyperpolarization of atrial cells due to increases in outward $\mathrm{K}+$ currents, and conduction abnormalities due to altered expression and localization of connexins that connect atrial myocyte. All of these conditions promote re-entry and chaotic patterns of atrial activation [17].

Atrial structural remodeling: The most significant aspects of structural remodeling include progressive atrial dilatation and 
the presence of fibrosis. Atrial fibrosis is a critical mechanistic importance to the development and maintenance of AF, by inducing heterogeneity of electrical conduction and predisposing to re-entry. It results from activation of fibroblasts which has classically been ascribed to ageing, comorbidities and multiple risk factors. Both animal studies and postmortem histological studies in humans support an association between $\mathrm{AF}$ and progressive atrial fibrosis. This means that AF directly induces atrial remodeling that supports the further induction and maintenance of AF. Fibrosis increases the separation of the myocyte within sub-endocardial atrial bundles and between the endocardial and epicardial layers, leading to endo-epicardial dissociation. It forms barriers to the propagation of the activation wave fronts and isolates atrial myocyte. These could induce spiral waves through vortex shedding or by causing localized conduction block in narrow isthmuses.

Furthermore, the fibrotic pattern affects the velocity of the activation wave fronts. In addition to fibrosis, atrial fatty infiltration, inflammatory infiltration, necrosis and amyloid deposition are also involved in the development of AF [18]. The infiltration of adipocytes into the atrial myocardium could also disorganize the depolarization wave fronts favoring micro re-entry circuits and local conduction block. This adipose tissue is likely to be a major player in the formation of the AF substrate given its important biological activity. It could be the missing link between $\mathrm{AF}$ and the clinical conditions associated with changes in the biological activity of cardiac adipose tissue, such as obesity, diabetes, or heart failure.

Atrial Autonomic and Neural Remodeling: Cardiac myocyte have a rich and complex extrinsic and intrinsic autonomic nervous system. It was demonstrated that this system plays a significant role in the initiation and possibly the maintenance AF. Neural remodeling including an increase in the atrial innervation occurs in different clinical situations. Studies in animal and in AF patients have demonstrated an increase in the density of sympathetic and parasympathetic innervation [19]. In addition, neural remodeling also occurs after myocardial infarction and cardiomyopathy and the modulation of the autonomic tone usually reduced the AF burden [20].

Genetic Predisposition: Genetic predisposition plays an important role in the occurrence of AF. Individuals with a family member affected by AF have a $40 \%$ greater risk of incident AF than those without an affected family member. AF is less prevalent in Blacks, Hispanics and Asians compared to Whites. More than 150 gene candidates were associated with $\mathrm{AF}$. The variants located close to the Paired-Like Homeodomain 2 (PITX2) genes on chromosome $4 q 25$ have the highest association with AF [21]. The genes and pathways demonstrated from such approaches may allow new insights into AF pathophysiology, and potentially reveal new therapeutic methods.

\section{Exercise and Risk of AF}

The cardiovascular benefits of regular exercise have been well demonstrated, including a significant reduction in cardiovascular morbidity and mortality for those meeting recommended guidelines. However, the impact of physical activity on the incidence of AF has been less clear. Furthermore, we need to define the optimal dose and duration of exercise for the prevention and treatment of $\mathrm{AF}$. Several studies have shown that AF incidence is lowest amongst the most physically active participants. In the Cardiovascular Health Study, participants in the highest quartile of physical activity had a $46 \%$ lower incidence of $\mathrm{AF}$, compared to those who were relatively sedentary [3]. In large cohorts of Swedish men and women, daily walking or cycling lowered the risk of AF by $12 \%$ and $19 \%$, respectively $[22,23]$. Conversely, in the Women's Health Study, physical activity did not reduce AF incidence in adjusted analysis [24]. Moreover, in the Atherosclerosis Risk in Communities study, physically active status is associated with a small reduction in risk of $\mathrm{AF}$ [25].

Recently, Jin and colleagues reported the results of very large cohort (501,690 individuals without preexisting AF) "A Nationwide Cohort Study in General Population" and illustrated that meeting the recommended key target range of physical activity was associated with the maximum benefit for $\mathrm{AF}$ risk reduction in the general population. The dose-response relationship between physical activity level and AF risk revealed a U-shaped pattern [26]. The controversial findings regarding exercise and AF may be due to many factors, including the presence of other confounding risk factors. Additionally, the determining methods for AF incidence vary widely, including regular electrocardiography (EKG) through to self-report for AF which can result in subjective bias and timevarying changes in exercise measurement.

\section{Endurance Exercise and AF}

The maintenance of a fit and active lifestyle can reduce the risk of AF. However, these benefits do not appear to extend to those who participate in endurance exercise far beyond the volume recommended in current guidelines. In 1986, Coelho et al. found that lone AF was presented in about 25\% (5 from 19) of athletes because of palpitations or documented arrhythmia [27]. Twelve years later, Karjalainen and colleagues reported that the prevalence of AF amongst endurance athletes from a cohort of orienteers far exceeded that of the non-athletes control group (5.3\% vs. 0.9\%) [28]. In 2002, Mont et al. demonstrated that the proportion of sports men amongst patients with lone $\mathrm{AF}$ was greater than seen in the general population (63\% vs. 15\%) [29]. Many further studies reinforced the findings that heavy exercise was a significant predictor of AF incidence. All of the studies showed that people who participated in heavy exercise were at a 4 -fold to 15 -fold increased risk of AF compared with the general, sedentary population. 
Furthermore, even the most active individuals aged $<50$ years in the general population (jogging for 5-7 days per week) had 1.7fold increased risk of AF [30-34]. In 2013, Thelle and colleagues reported the results of a study that included 309,540 Norwegian men and women that the risk of drug treated lone AF increases with declining resting heart rate in both sexes and with increasing level of self-reported exercise in men [6]. One year later, in a population of 509 elderly Norwegian men with a history of long-term endurance sport practice, Myrstad et al. demonstrated a higher incidence of AF compared with 1,768 elderly men in the general population, with an added risk of AF around 6.0\%. Interestingly, light and moderate leisure-time physical activity during the previous years reduced the risk of AF [5]. They summarized that the association between exercise intensity and risk of AF assumed a U-shaped pattern (Figure 2). In the same year, Drca and colleagues demonstrated that vigorous exercise at a younger age was associated with an increased risk of $\mathrm{AF}$, whereas walking/bicycling at older age was associated with a decreased risk of $\mathrm{AF}$ in 44,410 Swedish AF-free men, aged 45-79 years [22]. In 2015, Andersen et al. addressed that exercise capacity has a U-shaped association with arrhythmia, driven by a direct association with risk of $\mathrm{AF}$ and a U-shaped association with brady-arrhythmia. This study involved the participation of 1.1 million young Swedish men (median age of 18.2 years).

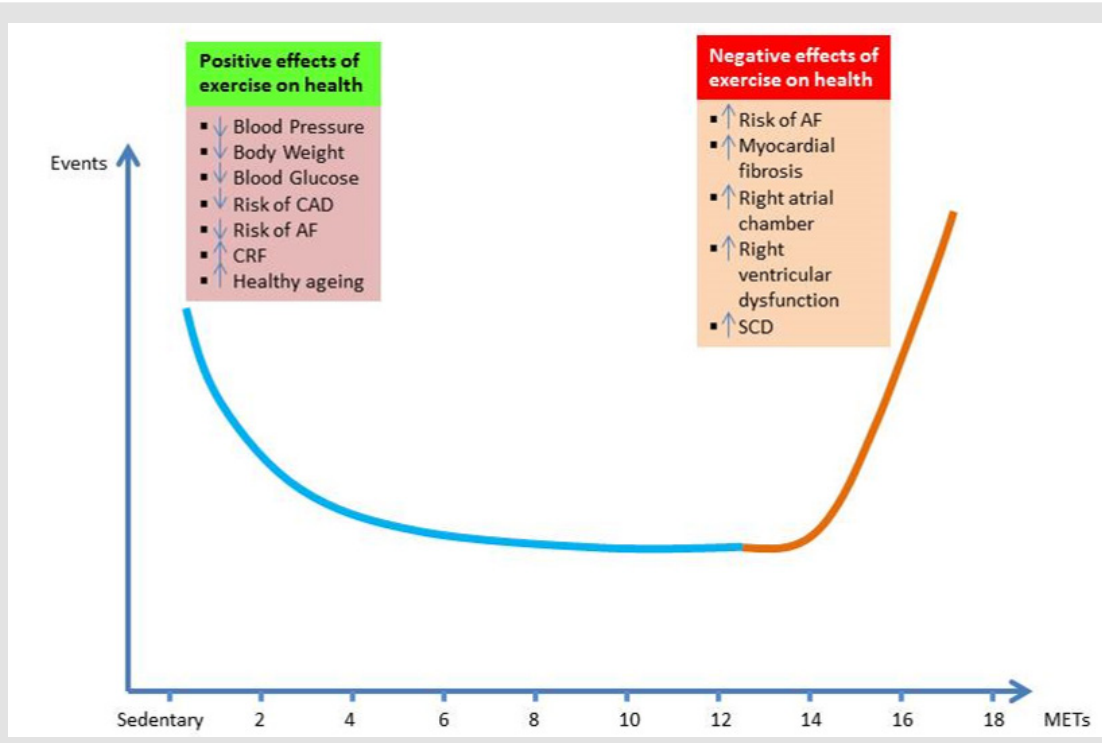

Figure 2: Exercise paradox, U-shape relationship between exercise doses and risk of atrial fibrillation $(\mathrm{AF})$. $\mathrm{CAD}=\mathrm{coronary}$ artery disease, $\mathrm{CRF}=$ cardiorespiratory fitness, $\mathrm{SCD}=$ sudden cardiac death, $\mathrm{MET}=$ metabolic equivalent of task $(1 \mathrm{MET}=$ the amount of oxygen consumed while sitting at rest $=3.5 \mathrm{ml} \mathrm{O}_{2}$ per $\mathrm{kg}$ body weight $\mathrm{x} \mathrm{min).}$

Individuals categorized in the quintiles with the highest fitness had 1.3-fold higher risk of $\mathrm{AF}$ than the quintiles that were least fit [35]. Recently, Svedberg and colleagues reported that men with higher number of races and faster finishing times had the highest incidence of AF. This case-control study included 783,102 participants (Swedish skiers $=208,654$ and matched sample of nonskiers $=527,448)$. Another large nationwide cohort study involved 501,690 individuals without pre-existing AF from Korea (mean age, $47.6 \pm 14.3$ years) demonstrated that meeting the recommended key target range of exercise was associated with maximal benefit for $\mathrm{AF}$ risk reduction in the general population. The dose-response relationship between intensity of exercise and AF risk showed a U-shaped pattern [36]. Another large population-based cohort of men and women from Norway $(n=20,484)$ reported that higher estimated cardiopulmonary fitness (eCRF) was inversely related to risk of AF. Men in the upper spectrum of eCRF did not have significant reduction in AF risk, suggesting a J-shaped pattern. Moreover, improved eCRF status over 20 years was associated with less AF compared to decreased eCRF levels [37].

\section{Mechanisms of AF in Endurance Exercise}

Although the pathophysiology of AF is complex, its initiation and maintenance are commonly due to a rapidly firing ectopic focus or through multiple circuit re-entries. However, the mechanisms that contribute to the excess of $\mathrm{AF}$ amongst endurance sports participants remain unclear. Studies from many investigators revealed that the mechanisms included alterations of autonomic tone, left atrial enlargement and fibrosis, electrical remodeling, and increased inflammation of the atrium (Figure 3) [38-43]. Clinical studies reported that at rest and during low-intensity physical activity, endurance athletes had dominant vagal tone compared with non-athletes. Not only increased vagal tone but also low heart rates were demonstrated to be strong contributing factors in increasing incidence of AF. Enhanced vagal activity is known to be shorten the atrial refractory period and combined with slowed atrial conduction velocity could facilitate re-entry. These modifications, often expressed as athlete's heart, are assumed to be physiological, reversible modifications to the increased demands during exercise [44]. 


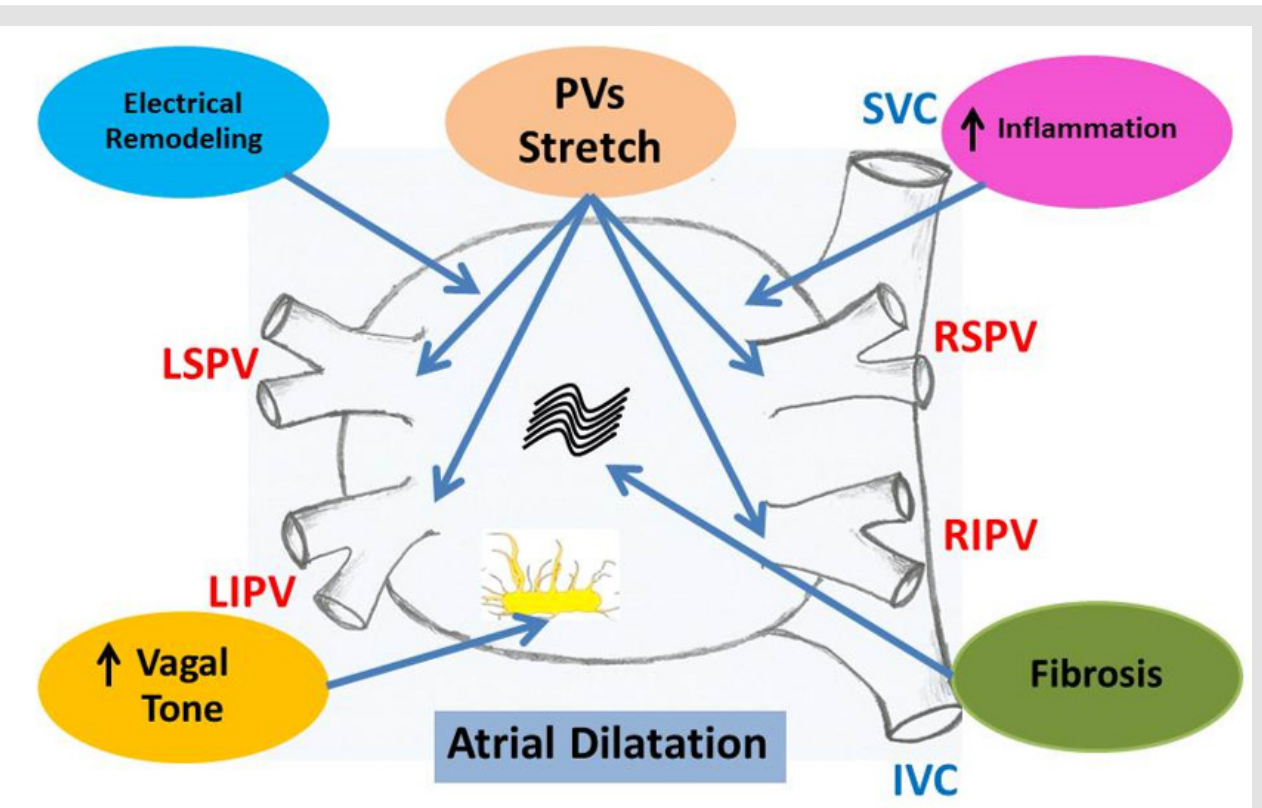

Figure 3: Possible mechanisms of $\mathrm{AF}$ in endurance exercise included alterations of autonomic tone, left atrial dilatation and fibrosis, electrical remodeling, and increased inflammation of the atrium. PVs = pulmonary veins, LSPV = left superior pulmonary vein, $\mathrm{RSPV}=$ right superior pulmonary vein, $\mathrm{LIPV}=$ left inferior pulmonary vein, $\mathrm{RIPV}=$ right inferior pulmonary vein, SVC = superior vena cava, IVC = inferior vena cava.

\section{Substrate: Atrial Remodeling}

The endurance training leads to a harmonic enlargement of all four cardiac chambers as an adaptation to exercise conditioning. Since the atrial walls are much thinner than the ventricular walls, atrial wall stress is higher during episodes of training-related volume overload and may contribute to progressive enlargement and remodeling of the atria. Iskandar and colleague reported the meta-analysis of 54 studies (7,189 elite athletes and 1,375 controls) that Left Atrium (LA) diameter was $4.1 \mathrm{~mm}$ greater in athletes compared with sedentary controls and LA volume index was 7.0 $\mathrm{ml} / \mathrm{m}^{2}$ greater in athletes than controls. They concluded that elite athletes have larger LA dimensions compared with controls when evaluated by either LA diameter or LA volume corrected for body surface area. The largest average LA diameters were reported in endurance athletes [45]. Pelliccia et al. demonstrated that In 114 Olympic athletes, extreme and uninterrupted endurance training over a period of 17 years was associated with an increase in left LA size, but Left Ventricular (LV) chamber remained stable. Additionally, endurance training influences the growing heart of preadolescent athletes with an additive increase in bi-atrial size, suggesting that morphological adaptations can also occur in the early phases of the sports career. Training-induced remodeling was associated with a preserved bi-atrial function, supporting the hypothesis of a physiological remodeling [46]. D'Andrea and colleagues reported that among a large population of highly trained athletes, a mild enlargement of LA volume index was relatively common and may be regarded as a physiologic adaptation to exercise conditioning [47].

\section{Modulators: Alterations of Autonomic Tone}

The autonomic nervous system plays a significant role in both initiation and maintenance AF. Both increased parasympathetic and increased sympathetic nervous system activity have been observed to facilitate AF in athletes. Most of the investigated data in athletes demonstrated that increased vagal tone was the principal mechanism of $\mathrm{AF}$ initiation. From the Grup Integrat de Recerca en Fibril-lació Auricular (GIRAFA) study, the origin of AF was vagal in $70 \%$ of patients [48]. Similarly, Grimsmo et al. found that bradycardia and long PQ time were predictors for the occurrence of lone AF [49]. Swanson et al. reported that gastroesophageal reflux may stimulate autonomic nervous system and induce AF [50]. Wilhelm and colleagues evaluated the impact of lifetime training hours of endurance athletes on signal-averaged P-wave duration and modifying factors. They established that in the high training group, vagal tone was significantly increased and premature atrial complexes were more frequent [38]. Stavrakis et al. demonstrated that the duration and inducibility of AF were suppressed noninvasively by low-level transcutaneous electrical stimulation of the auricular branch of the vagus nerve at the tragus. These results support the notion that autonomic neuro-modulation may emerge as an alternative non-pharmacological, non-ablative modality to treat paroxysmal AF [51]. A conversion from vagal to adrenergic predominance has been demonstrated in highly trained athletes prior to competitions. Adrenergic predominance favors automaticity and micro re-entries in structurally remodeled atrium. 


\section{Triggers: Atrial Ectopic Beats}

Atrial ectopic beats or premature atrial contractions can be generated from irritable foci anywhere in the atria. In particular, those originating from pulmonary veins have been shown to be the triggers in most episodes of paroxysmal AF. Atrial ectopic beats increased with age and also as a consequence of physical activity. It was proposed that increased atrial ectopic beats could explain the increased risk of AF associated with sport practice. However, these findings were not confirmed by Baldesberger and colleagues whose results did not find an increase in incidence of atrial ectopic beats in former professional cyclists [52]. Moreover, Elliott et al. could not demonstrate the increased vagal parameters or atrial ectopic beats in 99 recreational endurance athletes [53]. Hence, the hypothesis of increased atrial ectopic beats to explain the association between sports and AF cannot be adequately confirmed with the currently available data.

\section{Diagnosis}

$\mathrm{AF}$ is a supraventricular tachyarrhythmia characterized by uncoordinated atrial electrical activation and consequently ineffective atrial contractions. EKG demonstrates irregular RR intervals, absence of distinct repeating $\mathrm{P}$ waves, and presence of the fibrillatory waves ( $\mathrm{f}$ waves). During AF, the atria contract at a rate of 350-900 beats/min, conducting to the ventricles at a rate of $90-170$ beats/min [54]. Patients with AF may present with mild or no symptoms, heart failure, myocardial infarction, stroke, or hemodynamic collapse. Symptoms such as syncope, palpitations, and dyspnea on exertion reported by patients should be rigorously evaluated. A systematic review concluded that pulse rate is $94 \%$ sensitive and $72 \%$ specific for diagnosis [55]. A detailed history and a complete physical examination are an affirmative. Onset of symptoms with relation to exercise needs to be demonstrated. A history of the use of alcohol, sports supplements and energy drinks is an important data. All patients should undergo a standard testing which includes a basic metabolic panel to assess for any underlying electrolyte abnormalities, a thyroid panel and a transthoracic echocardiography. Holter monitor may be used to determine whether symptoms correlate with paroxysmal AF.

\section{Management}

In patients who are hemodynamically unstable, immediate evaluation and treatment are needed, including emergency cardioversion. In stable AF patients, treatment depends on the duration of $\mathrm{AF}$ and the presence of underlying cardiac diseases or other comorbidities. AF treatment poses three main therapeutic dilemmas including control ventricular rate, convert the rhythm back to normal sinus rhythm and start anticoagulant to prevent stroke and myocardial infarction in the future [56].

\section{Control Ventricular Rate}

The essential part of AF treatment is ventricular rate control. Reducing ventricular contraction will improve hemodynamic function and diastolic ventricular filling. It can also reduce myocardial oxygen demand and increase coronary perfusion and improve mechanical function. Ventricular rate control is the definitive treatment for AF which is considered to be permanent in nature. Most patients should be treated with either a cardiospecific beta-blocker or a rate-limiting calcium channel blocker. Beta-blockers are preferred in patients with left ventricular dysfunction and calcium channel blockers are advantageous in patients with Chronic Obstructive Pulmonary Disease (COPD) or asthma (Table 1) [57]. Amiodarone is suitable for patients with heart failure because of its powerful rate-limiting effect, but it has multiple toxicities. Lenient rate control to achieve a resting ventricular rate less than $110 \mathrm{bpm}$ is reasonable in the majority of patients. Strictly ventricular rate control less than $80 \mathrm{bpm}$ during rest may be appropriate if needed to resolve symptoms. However, beta-blockers and calcium channel blockers are contraindicated in patients with pre-excitation (e.g. Wolff-Parkinson-White syndrome) [58]. Moreover, in patients with acute heart failure, severe COPD and asthma, non-cardio selective beta-blockers are also contraindicated. In rare cases where ventricular rate control cannot be achieved by medication due to either drug intolerance or inefficiency, catheter-based treatment may be an alternative choice. Ablation of the atrio-ventricular junction, achieved by either radiofrequency current or deep freezing, leads to destruction of the functional connection between the atria and the ventricles [59]. 
Table 1: Drugs used for ventricular rate control in AF patients.

\begin{tabular}{|c|c|c|c|}
\hline Drugs & Maintenance dose & Preferable clinical setting & Adverse events \\
\hline $\begin{array}{l}\text { Diltiazem } \\
\text { Verapamil }\end{array}$ & $\begin{array}{l}20-360 \text { mg daily } \\
80-360 \text { mg daily }\end{array}$ & $\begin{array}{l}\text { Patients with asthma and chronic } \\
\text { obstructive pulmonary diseases }\end{array}$ & $\begin{array}{l}\text { Hypotension; atrioventricular } \\
\text { block; heart failure }\end{array}$ \\
\hline $\begin{array}{l}\text { Bisoprolol } \\
\text { Carvedilol } \\
\text { Nebivolol } \\
\text { Metoprolol } \\
\text { Atenolol }\end{array}$ & $\begin{array}{l}\text { 5-10 mg daily } \\
25-100 \mathrm{mg} \text { daily } \\
5-10 \mathrm{mg} \text { daily } \\
50-200 \mathrm{mg} \text { daily } \\
50-100 \mathrm{mg} \text { daily }\end{array}$ & $\begin{array}{l}\text { Patients with coronary artery } \\
\text { disease, myocardial infarction, } \\
\text { heart failure }\end{array}$ & $\begin{array}{c}\text { Hypotension; bradycardia; } \\
\text { atrioventricular block; } \\
\text { deterioration of chronic obstructive } \\
\text { pulmonary } \\
\text { disease or asthma; fatigue }\end{array}$ \\
\hline Sotalol & 80-320 mg daily & Recurrence of atrial fibrillation & $\begin{array}{l}\text { Hypotension; bradycardia; QT } \\
\text { prolongation; torsade de pointes }\end{array}$ \\
\hline Amiodarone & 200 mg daily & $\begin{array}{l}\text { Recurrence of atrial fibrillation; } \\
\text { limited use in permanent AF } \\
\text { because of multiple toxicities }\end{array}$ & $\begin{array}{l}\text { Bradycardia; prolong QT; } \\
\text { torsade de pointes; } \\
\text { photosensitivity; } \\
\text { pulmonary toxicity; } \\
\text { polyneuropathy; } \\
\text { hepatic toxicity; } \\
\text { thyroid dysfunction; } \\
\text { gastrointestinal upset }\end{array}$ \\
\hline
\end{tabular}

\section{Converting the Rhythm Back}

Rhythm-control strategy included all therapeutic interventions aimed at prevention of $\mathrm{AF}$ recurrences and restoration of sinus rhythm using a combination of approaches including cardioversion, antiarrhythmic drugs and catheter ablation. Restoration of sinus rhythm may be achieved by means of either antiarrhythmic drugs or delivery of electrical shock. Electrical cardioversion terminates AF immediately in more than $90 \%$ of all patients. However, it requires sedation, which itself is not a risk-free intervention and does not prevent immediate recurrence of AF. Pharmacological cardioversion, on the other hand, does not require sedation, but its success rate ranges only about $30-60 \%$. Moreover, it is more timeconsuming due to the time required for an antiarrhythmic drug to reach therapeutic concentration. Since rhythm-control strategy is the approach which aimed improving the quality of life rather than reducing the mortality, the choice of drug needs to be the safest one [60]. Electro-physiologic radiofrequency ablation is a non-operative, catheter-based procedure used to isolate and destroy abnormal foci responsible for AF. Specific foci that cause AF have been found to be at or near the pulmonary vein ostia in the left atrium and used as the target for radiofrequency ablation procedure. However, AF may recur after ablation, and a repeat procedure may be required in around $20 \%$ of AF patients. This procedure is contraindicated in patients who cannot be anti-coagulated one month before and at least several months after the procedure. Atrio-ventricular nodal ablation with pacemaker implantation may be beneficial for older patients with tachycardia induced cardiomyopathy and persons with refractory ventricular rate control despite maximal medical treatment [61].

\section{Start Anticoagulant}

Prevention of thromboembolic complications of AF can be achieved by administration of medications attenuating bloodclotting capacity to individuals at high risk of ischemic stroke. The significant aspect of anticoagulation therapy is maintaining the fine balance between the benefit of reducing propensity to clotting, the potential harm of the drugs related to the prolonging of bleeding time, and the risk of bleeding complications. The CHA2DS2-VA (Congestive heart failure, Hypertension, Age $>75$ years [2 points], Diabetes, Stroke/transient ischemic attack [2 points/1 point respectively], Vascular disease, Age $>65$ years) score has been used in clinical practice to predict stroke risk in AF. This has resulted in the following recommendations for both sexes: [62]

- $\quad \mathrm{CHA}_{2} \mathrm{DS}_{2}-\mathrm{VA}=0$ : Oral anticoagulants (OACs) are not recommended

- $\quad \mathrm{CHA}_{2} \mathrm{DS}_{2}-\mathrm{VA}=1$ : OACs should be considered

- $\quad \mathrm{CHA}_{2} \mathrm{DS}_{2}-\mathrm{VA}=2:$ OACs are recommended

Similar clinical tools are available for assessing anticoagulation bleeding risk. The HAS-BLED (Hypertension, Abnormal renal function and liver function, Stroke, Bleeding, Labile international normalized ratio, Elderly [age $>65$ years], Drugs and alcohol) scoring system has been well validated, with a score of 3 or more indicating that a patient has a high likelihood of hemorrhage [63]. Warfarin lowers the risk of thromboembolic events, but it has a narrow therapeutic range, multiple drugs and foods interactions, and requires frequent blood monitoring of the international normalized ratio (INR). Studies have shown that low-intensity warfarin in $\mathrm{AF}$ (INR $=1.5$ ) is not effective in preventing stroke. Aspirin alone or in combination with clopidogrel is an option for patients who decline or are unable to tolerate anticoagulants, or who are at low risk of stroke. Direct oral anticoagulants, including a direct thrombin and several factor Xa inhibitors, are available. Their main advantages compared with warfarin include fixed dosing, no food interactions, fewer drug interactions, and no need for INR monitoring. The major drawbacks are higher costs, difficulty reversing their effect in emergency situations, and the lack of simple blood tests to check drug levels. Table 2 outlines the pharmacologic properties of direct oral anticoagulants and warfarin [64]. 
Table 2: Pharmacological property of anticoagulants drugs which have been used for prevention of thromboembolism in patients with atrial fibrillation (AF).

\begin{tabular}{|c|c|c|c|c|c|c|}
\hline Drugs & Mechanism & Dosing & $\begin{array}{c}\text { Oral } \\
\text { bioavailability }\end{array}$ & $\begin{array}{l}\text { Time to } \\
\text { effect } \\
\text { (hours) }\end{array}$ & $\begin{array}{l}\text { Half-life } \\
\text { (hours) }\end{array}$ & Reversible \\
\hline Dabigatran & $\begin{array}{l}\text { Direct thrombin } \\
\text { inhibitor }\end{array}$ & $\begin{array}{c}-150 \mathrm{mg} \text { twice daily } \\
-75 \mathrm{mg} \text { twice daily for } \mathrm{CrCl} 15 \text { to } 30 \mathrm{~mL} / \mathrm{min} / 1.73 \\
\mathrm{~m}^{2} \\
- \text { Not recommended if } \\
\mathrm{CrCl}<15 \mathrm{~mL} / \mathrm{min} / 1.73 \mathrm{~m}^{2}\end{array}$ & $3-7 \%$ & $1-2$ & $12-17$ & Yes \\
\hline Apixaban & Factor Xa inhibitor & $\begin{array}{l}-5 \mathrm{mg} \text { twice daily } \\
-2.5 \mathrm{mg} \text { twice daily for patients with } \geq 2 \text { of the } \\
\text { following: } \\
\text {-creatinine }>1.5 \mathrm{mg} / \mathrm{dL} \\
\text {-age }>80 \text { years } \\
\text {-weight }<60 \mathrm{~kg}\end{array}$ & $58 \%$ & $3-4$ & $8-15$ & No \\
\hline Edoxaban & Factor Xa inhibitor & $\begin{array}{l}-60 \mathrm{mg} \text { daily } \\
\text {-30 mg daily if } \mathrm{CrCl} 15 \text { to } 50 \mathrm{~mL} / \mathrm{min} / 1.73 \mathrm{~m}^{2} \\
\text {-Not recommended if } \mathrm{CrCl}<15 \mathrm{~mL} / \mathrm{min} / 1.73 \mathrm{~m}^{2} \\
\text {--Avoid in Child-Pugh Class } \mathrm{B} \text { or C liver disease }\end{array}$ & $62 \%$ & $1-2$ & $10-14$ & No \\
\hline Rivaroxaban & Factor Xa inhibitor & $\begin{array}{l}-20 \mathrm{mg} \text { daily } \\
-15 \mathrm{mg} \text { daily for } \mathrm{CrCl} 15 \text { to } 50 \mathrm{~mL} / \mathrm{min} / 1.73 \mathrm{~m}^{2} \\
\text {-Not recommended if } \mathrm{CrCl}<15 \mathrm{~mL} / \mathrm{min} / 1.73 \mathrm{~m}^{2}\end{array}$ & $60 \%$ & $2-4$ & $5-9$ & No \\
\hline Warfarin & $\begin{array}{l}\text { Vitamin } \mathrm{K} \\
\text { antagonist }\end{array}$ & $\begin{array}{c}\text { Variable } \\
\text { (dose adjusted to INR) }\end{array}$ & $100 \%$ & $72-96$ & 40 & Yes \\
\hline
\end{tabular}

\section{Prevention of AF in Vigorous Exercise}

The World Health Organization (WHO) recommends that adults aged 18 - 64 years should engage in at least $150 \mathrm{~min} /$ week of moderate intensity exercise or $75 \mathrm{~min} /$ week of vigorous intensity exercise or an equivalent combination [65]. However, the dose-response association between exercise volumes and health outcomes is characterized by a U-shaped or reverse J-shaped curve $[26,37,43,66,67]$. So, it is of outmost importance to recognize if AF episodes are attributed to excessive exercise or not. In such cases, the initial approach is the reduction of the excessive exercise. The explanation of this improvement of the patients from $\mathrm{AF}$ is a reduction of exercise volume can shift the autonomic balance from elevated vagal tone towards a higher adrenergic tone and decrease the burden of vagally mediated AF. Furlanello et al. described a good response to sport abstinence in top-level athletes with $\mathrm{AF}$ [68]. Hoogsteen et al. also showed that up to $30 \%$ of athletes experienced fewer episodes of AF by reducing sport activity. They also demonstrated about the extrinsic factors which will affect $\mathrm{AF}$ occurrence in the endurance sport activities. These included long and intense periods of training could generate substantial shifts in body fluids due to changes in volume regulation, changes in potassium and sodium levels, high body temperature, hourly loss of 1 or 2 liters of body fluids, inappropriate fluid intake, and a significant loss in magnesium which can induce AF. All of these factors could be the confounders in the relationship between endurance exercise and AF [69]. It is mean that the prevention of $\mathrm{AF}$ in endurance exercise need to also aware about the risks from extrinsic factors.

\section{Conclusion}

The relationship between physical activity volume and AF risks reveals to be U-shaped or J-shaped pattern. The exercise at volumes of 5 - 18 MET-h/weeks may result in AF risks reduction. In contrast, volumes of exercise exceeding 18 MET-h/weeks may increase in AF risks. Moreover, endurance exercises are associated with several cardiac maladaptation which increased AF risks. The combination of endurance exercise in the presence of known or occult cardiac abnormality is the major cause of exercise induced fatalities. AF in endurance exercise causes serious symptoms that disturb sporting activity and reduce exercise tolerance and hence more attention should be paid to prevent it. The most effective prevention strategy is the reduction of the volume and the strength of endurance exercise.

\section{Funding}

This research received no specific grant from any funding agency in the public, commercial, or not-for-profit sectors.

\section{Conflict of Interest}

None.

\section{References}

1. Sattelmair J, Pertman J, Ding EL, Kohl HW, Haskell W (2011) Dose response between physical activity and risk of coronary heart disease: a meta-analysis. Circulation 124(7): 789 -795.

2. Kyu HH, Bachman VF, Alexander LT (2016) Physical activity and risk of breast cancer, colon cancer, diabetes, ischemic heart disease, and ischemic stroke events: systematic review and dose-response metaanalysis for the global burden of disease study 2013. BMJ 354: i3857. 
3. Mozaffarian D, Furberg CD, Psaty BM, Siscovick D (2008) Physical activity and incidence of atrial fibrillation in older adults: the cardiovascular health study. Circulation 118(8): 800-807.

4. Aizer A, Gaziano JM, Cook NR, Manson JE, Buring JE (2009) Relation of vigorous exercise to risk of atrial fibrillation. Am J Cardiol 103(11): 1572-1577.

5. Myrstad M, Løchen ML, Graff Iversen S (2014) Increased risk of atrial fibrillation among elderly Norwegian men with a history of long-term endurance sport practice. Scand J Med Sci Sports 24(4): e238-e244.

6. Thelle DS, Selmer R, Gjesdal K (2013) Resting heart rate and physical activity as risk factors for lone atrial fibrillation: a prospective study of 309,540 men and women. Heart 99(23): 1755-1760.

7. Andersen K, Farahmand B, Ahlbom A (2013) Risk of arrhythmias in 52755 long-distance cross-country skiers: a cohort study. Eur Heart ] 34(47): 3624-3631.

8. Bapat A, Zhang Y, Post WS (2015) Relation of physical activity and incident atrial fibrillation (from the Multi-Ethnic Study of Atherosclerosis). Am J Cardiol 116(6): 883 - 888.

9. Schnabel RB, Yin X, Gona P (2015) 50 year trends in atrial fibrillation prevalence, incidence, risk factors, and mortality in the Framingham Heart Study: a cohort study. Lancet 386(9989): 154-162.

10. Santangeli P, Di Biase L, Bai R (2012) Atrial fibrillation and the risk of incident dementia: a meta-analysis. Heart Rhythm 9(11): 1761-1768.

11. Lloyd Jones DM, Wang TJ, Leip EP (2004) Lifetime risk for development of atrial fibrillation: the Framingham Heart Study. Circulation 110(9): 1042 - 1046.

12. Bhatt HV, Fischer GW (2015) Atrial Fibrillation: Pathophysiology and Therapeutic Options. J Cardiothorac Vasc Anesth 29(5): 1333-1340.

13. Haissaguerre M, Shah AJ, Cochet $H$ (2016) Intermittent drivers anchoring to structural heterogeneities as a major pathophysiological mechanism of human persistent atrial fibrillation. J Physiol 594(9): 2387-2398.

14. Kampaktsis PN, Oikonomou EK, Y Choi D, Cheung JW (2017) Efficacy of ganglionated plexi ablation in addition to pulmonary vein isolation for paroxysmal versus persistent atrial fibrillation: a meta-analysis of randomized controlled clinical trials. J Interv Card Electrophysiol 50(3): 253-260.

15. Blandino A, Biondi Zoccai G, Battaglia A (2017) Impact of targeting adenosine-induced transient venous reconnection in patients undergoing pulmonary vein isolation for atrial fibrillation: a metaanalysis of 3524 patients. J Cardiovasc Med (Hagerstown) 18(7): 478489.

16. Corradi D, Callegari S, Gelsomino S, Lorusso R, Macchi E (2013) Morphology and pathophysiology of target anatomical sites for ablation procedures in patients with atrial fibrillation: part II: pulmonary veins, caval veins, ganglionated plexi, and ligament of Marshall. Int J Cardiol 168(3): 1769-1778.

17. Shiroshita Takeshita A, Brundel BJ, Nattel S (2005) Atrial fibrillation: basic mechanisms, remodeling and triggers. J Interv Card Electrophysiol 13(3): 181-193.

18. Schoonderwoerd BA, Van Gelder IC, Van Veldhuisen DJ, Van den Berg MP, Crijns HJ (2005) Electrical and structural remodeling: role in the genesis and maintenance of atrial fibrillation. Prog Cardiovasc Dis 48(3): 153168.

19. Chen PS, Tan AY (2007) Autonomic nerve activity and atrial fibrillation. Heart Rhythm 4(3 Suppl): S61- S64.

20. Yu Y, Wei C, Liu L, Lian AL, Qu XF (2014) Atrial fibrillation increases sympathetic and parasympathetic neurons in the intrinsic cardiac nervous system. Pacing Clin Electrophysiol 37(11): 1462-1469.

21. Choi JI, Baek YS, Roh SY, Piccini JP, Kim YH (2019) Chromosome 4q25 variants and biomarkers of myocardial fibrosis in patients with atrial fibrillation. J Cardiovasc Electrophysiol 30(10): 1904-1913.
22. Drca N, Wolk A, Jensen Urstad M, Larsson SC (2014) Atrial fibrillation is associated with different levels of physical activity levels at different ages in men. Heart 100(13): 1037-1042.

23. Drca N, Wolk A, Jensen Urstad M, Larsson SC (2015) Physical activity is associated with a reduced risk of atrial fibrillation in middle-aged and elderly women. Heart 101(20): 1627-1630.

24. Azarbal F, Stefanick ML, Salmoirago Blotcher E (2014) Obesity, physical activity, and their interaction in incident atrial fibrillation in postmenopausal women. J Am Heart Assoc 3(4): e001127.

25. Huxley RR, Misialek JR, Agarwal SK (2014) Physical activity, obesity, weight change, and risk of atrial fibrillation: the Atherosclerosis Risk in Communities study. Circ Arrhythm Electrophysiol 7(4): 620-625.

26. Jin MN, Yang PS, Song C (2019) Physical Activity and Risk of Atrial Fibrillation: A Nationwide Cohort Study in General Population. Sci Rep 9(1): 13270.

27. Coelho A, Palileo E, Ashley W (1986) Tachyarrhythmias in young athletes. J Am Coll Cardiol 7(1): 237-243.

28. Karjalainen J, Kujala UM, Kaprio J, Sarna S, Viitasalo M (1998) Lone atrial fibrillation in vigorously exercising middle aged men: case-control study. BMJ 316: 1784-1785.

29. Mont L, Sambola A, Brugada J (2002) Long-lasting sport practice and lone atrial fibrillation. Eur Heart J 23(6): 477-482.

30. Elosua R, Arquer A, Mont L (2006) Sport practice and the risk of lone atrial fibrillation: a case-control study. Published correction appears in Int J Cardiol 108(3): 332-337.

31. Mont L, Tamborero D, Elosua R (2008) Physical activity, height, and left atrial size are independent risk factors for lone atrial fibrillation in middle-aged healthy individuals. Europace 10(1): 15-20.

32. Molina L, Mont L, Marrugat J (2008) Long-term endurance sport practice increases the incidence of lone atrial fibrillation in men: a follow-up study. Europace 10(5): 618-623.

33. Baldesberger S, Bauersfeld U, Candinas R (2008) Sinus node disease and arrhythmias in the long-term follow-up of former professional cyclists. Eur Heart J 29(1): 71-78.

34. Abdulla J, Nielsen JR (2009) Is the risk of atrial fibrillation higher in athletes than in the general population? A systematic review and metaanalysis. Europace 11(9): 1156-1159.

35. Andersen K, Rasmussen F, Held C, Neovius M, Tynelius P (2015) Exercise capacity and muscle strength and risk of vascular disease and arrhythmia in 1.1 million young Swedish men: cohort study. BMJ 351: h4543.

36. Svedberg N, Sundström J, James S, Hållmarker U, Hambraeus K (2019) Long-Term Incidence of Atrial Fibrillation and Stroke Among CrossCountry Skiers. Circulation 140(11): 910-920.

37. Morseth B, Graff Iversen S, Jacobsen BK (2016) Physical activity, resting heart rate, and atrial fibrillation: the Troms $\varnothing$ Study. Eur Heart J 37(29): 2307-2313.

38. Wilhelm M, Roten L, Tanner H (2011) Atrial remodeling, autonomic tone, and lifetime training hours in nonelite athletes. Am J Cardiol 108(4): 580-585.

39. Guasch E, Benito B, Qi X (2013) Atrial fibrillation promotion by endurance exercise: demonstration and mechanistic exploration in an animal model. J Am Coll Cardiol 62(1): 68-77.

40. Turagam MK, Flaker GC, Velagapudi P, Vadali S, Alpert MA (2015) Atrial fibrillation in athletes: pathophysiology, clinical presentation, evaluation and management. J Atr Fibrillation 8(4): 1309.

41. Patterson E, Po SS, Scherlag BJ, Lazzara R (2005) Triggered firing in pulmonary veins initiated by in vitro autonomic nerve stimulation. Heart Rhythm 2(6): 624-631.

42. Wilhelm M (2014) Atrial fibrillation in endurance athletes. Eur J Prev Cardiol 21: 1040-1048. 
43. Ricci C, Gervasi F, Gaeta M, Smuts CM, Schutte AE (2018) Physical activity volume in relation to risk of atrial fibrillation. A non-linear metaregression analysis. Eur J Prev Cardiol 25(8): 857- 866.

44. Prior DL, La Gerche A (2012) The athlete's heart. Heart 89(12): 947-955.

45. Iskandar A, Mujtaba MT, Thompson PD (2015) Left Atrium Size in Elite Athletes. JACC Cardiovasc Imaging 8(7): 753-762.

46. Pelliccia A, Kinoshita N, Pisicchio C (2010) Long-term clinical consequences of intense, uninterrupted endurance training in olympic athletes. J Am Coll Cardiol 55(15): 1619-1625.

47. D Andrea A, Formisano T, Riegler L (2017) Acute and chronic response to exercise in athletes: the "supernormal heart". Adv Exp Med Biol 999: 21-41.

48. Mont L, Tamborero D, Elosua R (2008) Physical activity, height, and left atrial size are independent risk factors for lone atrial fibrillation in middle-aged healthy individuals. Europace 10(1): 15-20.

49. Grimsmo J, Grundvold I, Maehlum S, Arnesen H (2010) High prevalence of atrial fibrillation in long-term endurance cross-country skiers: echocardiographic findings and possible predictors--a 28-30-year follow-up study. Eur J Cardiovasc Prev Rehabil 17(1): 100-105.

50. Swanson DR (2008) Running, esophageal acid reflux, and atrial fibrillation: a chain of events linked by evidence from separate medical literatures. Med Hypotheses 71(2): 178-185.

51. Stavrakis S, Humphrey MB, Scherlag BJ (2015) Low-level transcutaneous electrical vagus nerve stimulation suppresses atrial fibrillation. J Am Coll Cardiol 65(9): 867-875.

52. Baldesberger S, Bauersfeld U, Candinas R (2008) Sinus node disease and arrhythmias in the long-term follow-up of former professional cyclists. Eur Heart J 29(1): 71-78.

53. Elliott AD, Mahajan R, Linz D (2018) Atrial remodeling and ectopic burden in recreational athletes: Implications for risk of atrial fibrillation. Clin Cardiol 41(6): 843-848.

54. Schotten U, Hatem S, Ravens U (2015) The European Network for Translational Research in Atrial Fibrillation (EUTRAF): objectives and initial results. Europace 17(10): 1457-1466.

55. Gutierrez C, Blanchard DG (2016) Diagnosis and treatment of atrial fibrillation. Am Fam Physician 94(6): 442-452.

ISSN: 2574-1241

DOI: 10.26717/BJSTR.2020.28.004640

Wattana Leowattana. Biomed J Sci \& Tech Res

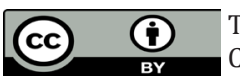

This work is licensed under Creative Commons Attribution 4.0 License

Submission Link: https://biomedres.us/submit-manuscript.php
56. Prystowsky EN, Padanilam BJ, Fogel RI (2015) Treatment of atrial fibrillation. JAMA 314(4): 278-288.

57. Park CS, Lee HY (2017) Clinical utility of sympathetic blockade in cardiovascular disease management. Expert Rev Cardiovasc Ther 15(4): 277-288.

58. Patel PA, Ali N, Hogarth A, Tayebjee MH (2017) Management strategies for atrial fibrillation. J R Soc Med 110(1): 13-22.

59. Mc Callum CJ, Raja DC, Pathak RK (2019) Atrial fibrillation: an update on management. Aust Prescr 42(6): 186-191.

60. Waks JW, Zimetbaum P (2017) Antiarrhythmic drug therapy for rhythm control in atrial fibrillation. J Cardiovasc Pharmacol Ther 22(1): 3-19.

61. Bhatti A, Oakeshott P, Dhinoja M, Grapsa J (2019) Ablation therapy in atrial fibrillation. BMJ 367: 16428.

62. Brieger D, Amerena J, Attia JR (2018) National Heart Foundation of Australia and Cardiac Society of Australia and New Zealand: Australian clinical guidelines for the diagnosis and management of atrial fibrillation 2018. Med J Aust 209(8): 356-362.

63. Methavigul K, Methavigul R (2019) Use of simplified HAS-BLED score in patients with atrial fibrillation receiving warfarin. J Arrhythm 35(5): 711-715.

64. Steinberg BA, Piccini JP (2014) Anticoagulation in atrial fibrillation. BM] 348: g2116.

65. WHO global recommendations on physical activity for health. accessed at February 4th 2020. https://www.who.int/dietphysical activity/ factsheet_adults/en/

66. Bosomworth NJ (2015) Atrial fibrillation and physical activity: Should we exercise caution? Can Fam Physician 61(12): 1061-1070.

67. Eijsvogels TMH, Thompson PD, Franklin BA (2018) The "Extreme Exercise Hypothesis": recent findings and cardiovascular health implications. Curr Treat Options Cardiovasc Med 20(10): 84.

68. Furlanello F, Bertoldi A, Dallago M (1998) Atrial fibrillation in elite athletes. J Cardiovasc Electrophysiol 9(8 Suppl): S63-S68.

69. Hoogsteen J, Schep G, Van Hemel NM, Van Der Wall EE (2004) Paroxysmal atrial fibrillation in male endurance athletes. A 9-year follow up. Europace 6(3): 222-228.

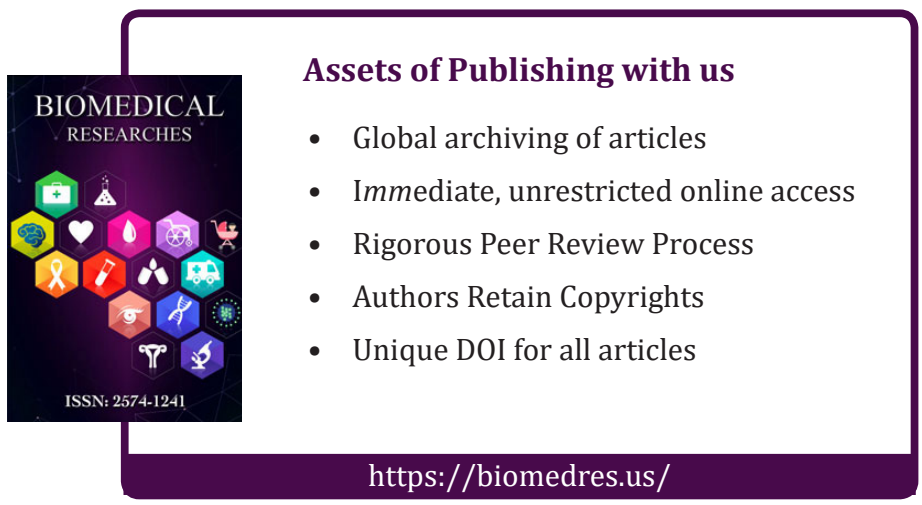

